\title{
Flash mob: a multidisciplinary review
}

\author{
Samer Al-khateeb ${ }^{1}\left(\mathbb{0} \cdot\right.$ Nitin Agarwal ${ }^{2}[0$
}

Received: 10 February 2021 / Revised: 15 July 2021 / Accepted: 17 July 2021 / Published online: 13 October 2021

(c) The Author(s), under exclusive licence to Springer-Verlag GmbH Austria, part of Springer Nature 2021

\begin{abstract}
Since the year 2003, the term "flash mob" has been studied in various disciplines and was referred to by various media outlets to describe various events. The term "flash mob" originally meant to describe a phenomenon in which a group of people assembles in a public space, perform a seemingly random act, then quickly disperse. This phenomenon was expected to die just like other types of public performances, e.g., the eighties' raves. However, this phenomenon is still alive and became widespread in various forms. Since this phenomenon was new, mentioned in the media, and depended on technology, it is unwise to assume that everyone knows its exact meaning. Many traditionalist flash mobbers become concerned that the global diffusion of flash mobs has diluted their original meaning. So, in this summative, chronological, and by topic literature review article, we explore the disciplines in which this term was used; then investigate its various forms and propose the term "Mob" to be the root term so we can categorize its various forms (branches) and eliminate ambiguities; and prove that this phenomenon still exists. Finally, we try to shed light on what is missing from the literature and what needs to be studied in the future with regard to this topic.
\end{abstract}

Keywords Mob $\cdot$ Flash mob $\cdot$ Smart mob $\cdot$ Deviant cyber flash mob $\cdot$ Rob mob $\cdot$ Social media

\section{Introduction}

In June of 2003, Bill Wasik, the current deputy editor of the New York Times Magazine, organized the first known mob at the home furnishing department of Macy's in Manhattan as a social experiment for his MOB project (Nicholson 2005; Walker 2011). This public performance meant to poke fun at the hipster's community and to be pointless with no strategy and no intent (Tan and Bakar 2015). Bill sent an invitation email to many people with the event details such as the time, location, and what to do instructions. He also asked the invitees to forward his email to anyone they know would be interested in participating in such an event. Around 150-200 people showed up at Macy's asking the salesperson about a $\$ 10,000$ love rug which they are interested in

Samer Al-khateeb

sameral-khateeb1@creighton.edu

Nitin Agarwal

nxagarwal@ualr.edu

1 Department of Computer Science, Design and Journalism, Creighton University, Omaha, NE, USA

2 Collaboratorium for Social Media and Online Behavioral Studies (COSMOS), University of Arkansas at Little Rock, Little Rock, AR, USA buying for their "free-love commune". Ten minutes later, they all dispersed (Tan and Bakar 2015). Soon this phenomenon was called a "flash mob" by participants and the local media (Walker 2011) as an analogy to a "flash flood" where all participants arrive at once, then disperse within minutes just like water from a sudden storm (Wasik 2011; Bylieva 2018). Many people, including Wasik himself, believed that this phenomenon would be dead within a year of its inception (Bylieva 2018) just like other forms of performances, for example, the eighties' raves or "rave" 1 in the late 1980s (Gore 2010). However, the flash mob phenomenon has become widespread. In July of 2004 the word "flash mob" was added to the Oxford English Dictionary (Nicholson 2005; Gore 2010; Molnár 2014) and since then it has been widely used in various disciplines, sectors of society, or scenarios to get a certain thing done collectively by mobilizing $^{2}$ a set of people in virtual and/or physical spaces. For example, the year 2011 was described as "the year of

\footnotetext{
1 The "Rave" is a movement that originated in England in the 1980s and moved to the USA early 1990s. The movement featured "acid house" parties that usually involve acid house music, drug use such as methylenedioxyamphetamine (MDMA), and held in places like aircraft hangars, warehouses, or barns ("Raves/Raving" 2021).

2 It's worth noting that the anti-globalisation movement which appeared at around the end of 1999 (Warner 2005) is one of the first protest movements to use mass mobilization and mobile communi-
} 
the flash mob" (E. Staff 2011) as claimed by David Downs, a San Francisco Examiner Staff. This phenomenon has also become widespread internationally. For example, Improv Everywhere, a New York-based company, organized various popular international flash mobs (Tan and Bakar 2015) such as "The Mp3 Experiment $t^{3}$, which took place in various cities around the globe such as Hong Kong, Bucharest, Oslo, Singapore, Berlin, etc.

Another term closely related to the term flash mob is "smart mob". It was coined in 2002 by Howard Rheingold, an American critic, in his book, "Smart Mobs: The Next Social Revolution" (Rheingold 2002) to refer to flash mobs that has agenda which can be political, sociological, economic, commercial, or religious, however, the term "flash mob" is more popular than "smart mob", even though the first term was used after the latter. Many journalistic accounts have reported that this form of public engagement has the potential to pose considerable amounts of risks to the civil, political, social, and economic stability of a region. For example, in 2010 the Greenpeace, a non-governmental organization in Zürich, Switzerland, organized the antinuclear flash mob "drop dead" in Zurich (Daily Express Newspaper 2010) to be more than just classical or regular flash mobs, i.e., a flash mob with agenda (Bylieva 2018).

In recent years "flash mobs have taken a darker twist as criminals exploit the anonymity of crowds, using social networking to coordinate everything from robberies to fights to general chaos" (Tucker and Watkins 2011; Steinblatt 2011). More recently, the term "mob" has been increasingly used to remark an electronically orchestrated violence such as the recent attack on the State Capital in Washington by angry protesters that lead to property damages, government disruption, and injuries or death for some of the protesters (W. P. Staff 2021; Barry et al. 2021). In a recent incident, an army of small investors from all over the world used Reddit to coordinate "flashmob investing" (Pratley 2021) to create a stock market frenzy causing GameStop's stock value to rise from $\$ 20$ to $\$ 483$ in less than a month (Brignall 2021). Such events raise the importance of systematically studying such behaviors. Modern information and communication technologies (ICTs) provide affordable and easy to use means of communications (such as social network platforms, viral emails, and SMS) that facilitates and ease the process of recruiting, training, and looking for a specific sector of the society, e.g., specific gender, age, political affiliation,

\footnotetext{
Footnote 2 (continued)

cation to create an organized collective action amongst participants (Nicholson 2005; Gore 2010; Molnár 2014; Shawyer 2008).

3 Watch the video https://www.youtube.com/watch? $\mathrm{v}=1 \mathrm{rCnh} 9 \mathrm{sT}$ mc\&ab_channel=ImprovEverywhere (accessed on June 20, 2021).
}

interest, and cultural background. This in turn has led to an increase in the occurrences of emerging socio-technical behaviors (Mohilever 2012), including flash mobs. A flash mob or mob, in general, can be considered successful when it succeeds to achieve its goal(s). Mobs can have various goals as explained later in this article ranging from using mob as an educational tool/research method to creating a political or social change to confusing citizens and creating chaos. With the increasing number of organized violent "protests" in recent months, there is a need to systematically study such events and be able to build predictive models to distinguish between benign and deviant/violent/vicious flash mobs. Also, it is essential to discover if a flash mob is still being practiced by organizations/individual groups to be able to predict its effect and build tools that enable authorities to intervene when a flash mob takes a violent or illegal turn.

Of course, when a phenomenon is new, mentioned in media, and depends on technology, it is hard to assume that everyone knows its exact meaning (Houston et al. 2013). Also, many traditionalist flash mobbers became concerned that the global diffusion of flash mobs have diluted their original meaning (Molnár 2014). So, in this summative, chronological, and by topic literature review article, we seek an answer to the following research questions:

1. How is the term "Flash Mob" used in the literature? What themes or topics it appears at?

2. What are the different forms of flash mobs studied in the literature?

- What are the common and most agreed-upon properties that define each of these forms?

- Can we categorize them based on their common properties?

3. Is the "flash mob" phenomenon dead as it was claimed by its creator or is it still alive? are there some organizations that still organize flash mobs?

The purpose of this research is to provide a scholarly overview of such a phenomenon to define and categorize its various forms to remove ambiguities. To the best of our knowledge, no research has done this. The rest of the article proceeds as the following: first, we explain the methodology we used to pick the scholarly articles analyzed in this paper. Second, we present our summative, chronological, and by topic literature review. Third, we discuss our findings, address the research questions mentioned above, and highlight the gabs we found in the literature on this topic. Fourth, we talk about the possible limitations of this work. Finally, we conclude our study with possible future research directions. 


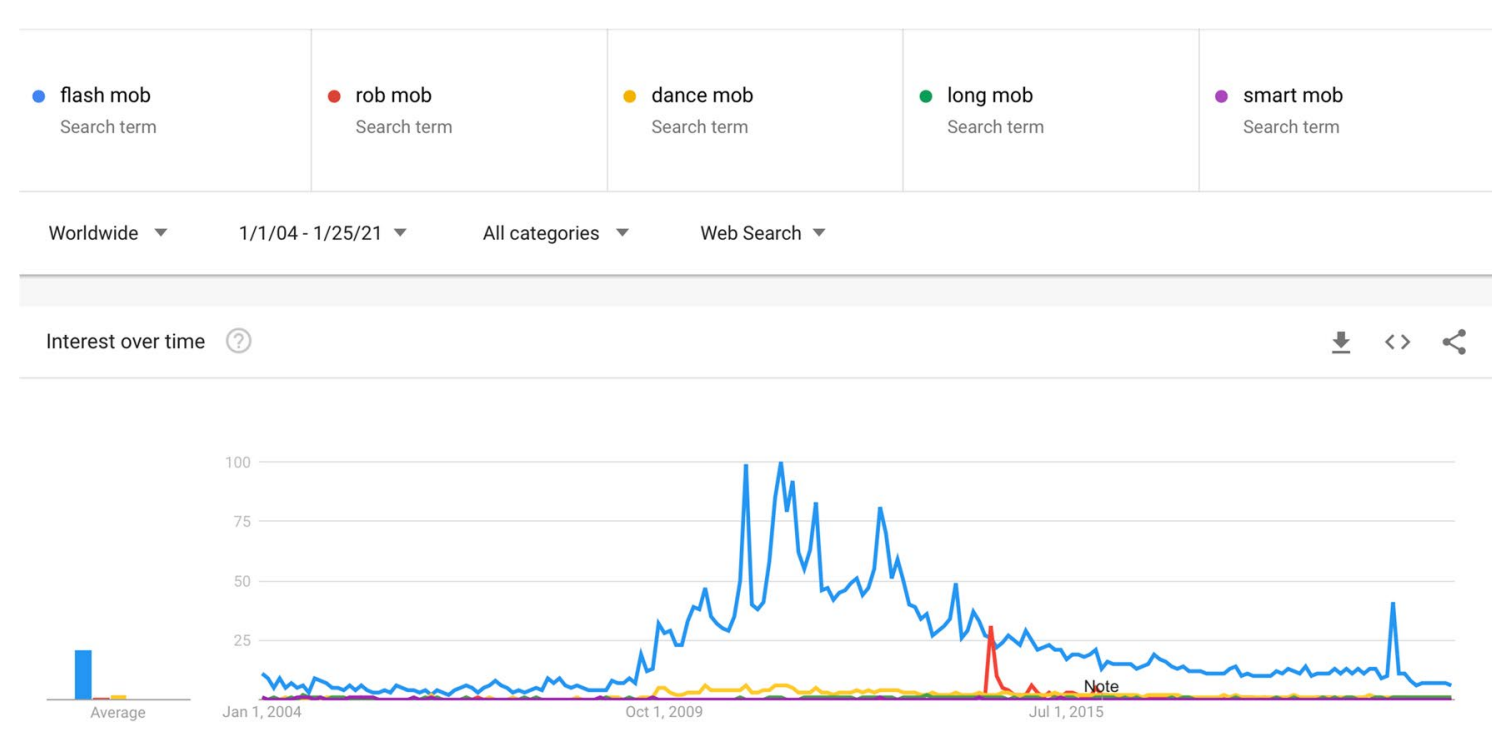

Fig. 1 Trend graph of the five most searched terms worldwide. Flash mob is the most searched term for the past 16 years. Note that this is how far back Google Trends allows us to go

\section{Methodology}

For this literature review, we used three search engines namely: Google Scholar, IEEE Xplore, and the ACM Digital Library. We used Google Scholar, because of its ease of use and accessibility (free and does not require any subscription), to search for peer-reviewed articles and conference proceedings that are written in English language, free, and contain the word flash mob. We picked the term flash mob because it was the most popular/searched term worldwide and over time (January 1, 2004-January 25, 2021) according to Google Trends. ${ }^{4}$ Figure 1 shows the popularity of the "Flash Mob" term along with other terms used to describe a similar type of event. These terms are ranked from most popular to least popular as follows: flash mob, rob mob, dance mob, long mob, and smart mob. We examined the first ten pages of the results (i.e., 100 research papers in total) returned by Google Scholar on January 25, 2021, using the keyword mentioned above. Then we cross-checked the results returned with the results of identical queries returned from IEEE Xplore and the ACM Digital Library. This process resulted in 33 relevant articles that we analyze below. Most of these articles were published between 2005 and 2019, with two peaks in 2011 and 2015. We picked the first ten pages of the results (i.e., the first 100 research articles) as research proved that Google Scholar usually has a good amount of trustworthy resources returned in the first few

\footnotetext{
${ }^{4}$ Google Trends is a website by Google that shows information about the popularity of search queries across various regions and languages since January 1, 2004 (“Google Trends” 2006, 2021).
}

pages and more gray literature ${ }^{5}$ is returned around/after page 80 of the search results (Haddaway et al. 2015).

\section{Literature review}

In this section, we try to capture a snapshot of the major themes in the literature of flash mobs to understand how the flash mob term has been chronologically used in various disciplines, topics, or themes. Below, we review the extant literature and categorize the research articles we collected into the following disciplines:

\subsection{Software systems}

In 2011, research conducted by Sykes et al. (2011) proposed a distributed adaptive self-assembly system ${ }^{6}$ called "FlashMob". In this model, they used the aggregate gossip protocol where a node is permitted to send several updates, compute some function using the information received, then

\footnotetext{
${ }^{5}$ Grey literature is "the unpublished, non-commercial, hard-to-find information that organizations such as professional associations, research institutes, think tanks, and government departments produce" (Shannon 2020).

${ }^{6}$ Adaptive self-assembly systems are systems that can change their behavior according to the change in the environment (Bruni et al. 2015). In such a system, which has a set of components already working, the system can find a new state that is better suited (e.g., in terms of its non-functional properties, for example, performance, reliability, and cost) for the change in the environment. There are several examples of self-assembly systems such as self-driving cars, web-server systems, unmanned underwater vehicles (Thomas 2020).
} 
propagate the result to the other nodes in the network. If all the nodes continue to send the information indefinitely the aggregate gossip protocol is called anti-entropy, on the other hand, if the nodes decide to stop at a specific point or round then the aggregate gossip protocol is called rumormongering. Their system uses a uniform push (anti-entropy) algorithm, in which a single update will propagate across the network. The authors applied their model on a simple robotic system (comprised of a Koala cart and Katana Arm) and using more complicated experiments comprised of simulated nodes on 80 desktop systems. They found that the model is proved to be suitable for such applications, scalable to largest and more complicated systems, and robust to message loss and node failures (Sykes et al. 2011). In the aforementioned research article, the term "flash mob" is used to refer to a method that can be used to improve the performance of adaptive self-assembly systems.

\subsection{Education}

In 2011, research conducted by Zellner et al. (2011) discusses the use of flash mobs as an education tool in university settings. The authors start by examining the root of flash mobs which they found to be in art because a flash mob represents an estranged artistic expression to re-purposes the nature of public spaces. Then explained the difference between a flash mob (usually for fun) and a smart mob (participants in such events have an agenda that could be political, sociological, or political). Finally, they discussed the educational affordances of flash mobs by reviewing four case studies namely:

- Flashmob: Pregnant women break-dancing in London ${ }^{7}$ which was organized by nonprofit Oxfam to bring awareness to maternal health in third world countries.

- Gotta Keep Reading-Ocoee Middle School ${ }^{8}$ which was executed by Black Eyed Peas and Oprah in 2009 to encourage middle school students to read and be ready for their Florida Comprehensive Assessment Test (FCAT).

- Use of Flash Mob as Point of Inquiry when John Landis, who is an elementary school teacher in Philadelphia,

\footnotetext{
${ }^{7}$ Watch the video: http://www.youtube.com/watch?v=Cs0s_K1IIAg (accessed on June 20, 2021).

${ }^{8}$ Watch the video: https://www.youtube.com/watch?v=vY9goJVX32 I\&ab_channel=Andr3wMacomb3r (accessed on June 20, 2021).
}

noticed his students are not doing well in the national test. So, he decided to teach his students reading comprehension. Students picked the flash mob topic to read about it, then analyzed various flash mob events that happened in Philadelphia (and organized by teenagers), created video games, then finally wrote and created media that emphasized the choices students must make in their own lives.

- National Day on Writing Flash mob: You, Too, Can Execute a Smart Mob when Andrea Zellner, one of the paper authors, joined by an enthusiastic choreographer took the challenge of organizing a smart mob at Michigan State University to raise awareness around the National Day on Writing. Andrea used her personal Twitter account, blog, and Facebook event page to communicate with participants. Then used university listservs to invite people to participate. The flash mob was scheduled to be held on October 20,2010, the same day as the National Day on Writing. Due to various factors, such as lack of community sense in the university, time conflict with work and school, and crowdedness of the public areas, the flash mob execution was hard but still raised some awareness as anticipated (Zellner et al. 2011).

In the same realm in 2012, Wendy Venning (Venning 2012) studied the use of flash mob as a teaching and learning tool. He used it to teach entry-level Japanese language to foundation years students (age does not exceed 8 years) in Australia. He emphasizes that flash mob is an ideal tool to teach foreign languages for young learners as it guarantees to engage them in a productive, fun, and physical learning experience, all of which perfectly align with the requirements of The Australian Curriculum, Assessment and Reporting Authority (ACARA) to teach kids the Japanese language. He organizes a flash mob each year so students can participate. He found this practice to be a very successful teaching method. He concludes that flash mobs are not only teaching and learning tools but also highly successful tools for Japanese program advocacy as they attracted the attention of parents, teachers, and national newspapers in Australia (Venning 2012).

In 2015, Tan and Bakar (2015) used the environmental manipulation method to study flash mob as an unplanned social event for her events management class. Around 45 students showed up in a mall in Singapore then started to dance in celebration of the Lunar New Year. These students were given the time, the location, and instructions on what to do for the event. Their participation was voluntary. Data before, during, and after the event were collected in various forms, including questionnaires, observation, and qualitative interviews. The researchers found that students, in general, 
enjoyed the flash mob event and stated that they learned what "cannot be covered in class, and they learning beyond the theory" (Tan and Bakar 2015). In all the aforementioned cases in this subsection, flash mobs have been utilized in educational environments to successfully improve students' literacy.

\subsection{Biomedical research}

Other researchers have used the flash mob research method to conduct a single-day experiment to study "the accuracy of recorded respiratory rates in inpatients" (Semler et al. 2013). In 2012, the internal medicine chief residents in six participating medical centers across the USA designed and implemented a flash mob research method. They created a collaborative network that involved more than 75 residents who they engaged and trained (residents participated in the study design, data collection, and analysis) according to a protocol put by internal medicine chief residents to conduct this clinical study. They collected data from 368 patients in 1 day across the six participating centers. Respiratory rate is one out of the five vital signs (pulse rate, blood pressure, body temperature, oxygen saturation, and respiratory rate) that are measured for hospitalized patients and can be used as early indicators of various diseases such as respiratory failure and sepsis. Most of the vital signs are measured in an automated and noninvasive manner, however, respiratory rate is measured manually for patients who are not mechanically ventilated. Many studies have concerns about the accuracy of measurements for these vital signs, especially respiratory rate as it is the only one measured manually, e.g., respiratory rate may be counted for 15 or $30 \mathrm{~s}$ and then multiplied by four or two to get the rates per minute. They proved that the recorded respiratory rates of hospitalized patients are higher than the directly observed measurements. They also proved that a flash mob can be used as a research method to conduct large-scale clinical studies.

In 2017, another set of researchers (Alsma et al. 2017) used flash mob as a research method to study Capillary Refill Time $^{9}$ (CRT). They used the interobserver agreement ${ }^{10}$ to evaluate CRT across the Netherlands in 2014. The researchers advertised for their study using social media, word-ofmouth, and conventional media. They were able to collect data of 1,734 patients from 38 Dutch hospitals by utilizing 458 investigators in a single day. The flash mob research method proved to be a valuable tool to research a simple clinical question in a fast, cost-effective, and reliable manner.

\footnotetext{
9 CRT: "is a clinical test used to evaluate the circulatory status of patients" (Alsma et al. 2017).

10 Interobserver Agreement (IOA) is "one of the most commonly used indicators of measurement quality in Applied Behavior Analysis (ABA) and it is the degree to which two or more observers report the same observed values after measuring the same events" (Gilmore, MSW, and read 2015).
}

And finally, a recent study conducted in 2019 by Schols et al. (2019) evaluated the Marburg Heart Score (MHS) which is a clinical decision rule that is used to determine whether patients have Acute Coronary Syndrome (ACS) or not. They also evaluated the feasibility of using flash mob as a research method to investigate research questions using a large scale, cost-effective, and rapid way for family medicine. The problem of evaluating the MHS or come up with a new decision rule for family physicians is a hard research problem due to the widespread (geographically) of family medicine clinics and the low number of relevant patients (with ACS). So, the researchers used a research method that mimics the flash mob phenomenon to investigate one research question. Their goal was to collect many samples in a short period of time for the study. The study lasted for 2 weeks toward the end of 2017 across the Netherlands. A steering committee invited a set of family physicians and their organizations to act as ambassadors. The steering committee and the ambassadors advertised the study using various professional and social channels including but not limited to social media, emails, personal websites, etc. They were able to collect data about 258 patients by mobilizing around 1,800 family physicians. They proved the feasibility to use flash mob as a research method to collect a large sample of data in a short period of time for large-scale family medicine research (Schols et al. 2019). In all the research mentioned in this subsection, flash mobs have been used as successful research tools to study simple clinical questions.

\subsection{Communication studies}

An article published in 2005 by Judith Nicholson (Nicholson 2005 ) focuses on the effects of mobile communication (calling, texting, and mobile video recording then posting) on the popularity of the flash mob phenomenon and how people became the receivers and transmitters of information in the new digital communication era. She gave examples in which mobile communications had been directly used in flash mobs such as the "yes, yes then applauding" flash mob that happened in Berlin in August of 2003 or the furniture admirers flash mob that happened in a sofa store on Tottenham Court Road in London around the same time. She concludes that even though the idea of crowd, mob, or mass existed historically, mobile communication is a key factor in the widespread popularity of flash mobs (in different political and cultural contexts) since the year 2003 (Nicholson 2005).

Another research published in 2017 by Aaron Shapiro (Shapiro 2017), focuses on the power of the flash mobitself-as a political tool and NOT on the role and effects of the communication technologies on the flash mobs. He argues that political flash mobs are not the result of the 
emergent of various new digital media technologies-as many pieces of research acclaim - but these political (sometimes violent) flash mobs (he calls them "vicious" flash mobs) are reflections of the injustices and lack of needs in specific communities. He also adds that such flash mobs are needed in various societies to maintain common sentiments that can be viewed as an affirmation of social order or a threat to social order (when they become violent). In any case, the occurrences of such flash mobs (whether they are an affirmation or a threat to social order) are somehow related to the excessive social categorization that happens in societies (Shapiro 2017).

A more recent article that is published in 2018 by Bylieva (2018) discusses the effects of the new digital communication technologies, e.g., Social Media, on modern society. The author's used methods of social analysis to analyze more than 1000 flash mobs. Their data were collected from various social media sites using the hashtag \#flashmob. They gave a good historical analysis of how flash mobs transformed from being flash mobs (with an artistic creativity principle) to smart mobs (with the capability of shedding a light on a problem and solving it). They identified the trends in the flash mobs' development as being "creative, game, business, and smart" (Bylieva 2018) with key characteristics of each development stage. The pieces of research mentioned in this subsection discuss the power of flash mobs as a free tool for citizens - of specific communities-to express their sentiments using the new forms of digital communication technologies or the effect of these communication technologies on the popularity of the flash mobs.

\subsection{Marketing}

Another field that leverages the idea of a flash mob is marketing. Research conducted by Nora Barnes in 2006 (Barnes 2006), discusses the use of flash mob as a marketing strategy for selling goods and services. She reviewed various collective behavior literature to analyze the flash mobbers' behavior. She described the mobbers as solidaristic (not individualistic), focused (not volatile), and active (not expressive). Then she used the collective behavior theory of Turner and Killian (Turner and Killian 1957) to provide a framework for understanding the formation and the power of flash mobs. Finally, she suggests that marketers should replicate flash mobs without the mobber's awareness as it would increase the effects of the flash mobs, e.g., a store can invite a set of consumers by sending them emails, or other forms of communication, to the store and have them do something silly and fun at one of its corners then provide the mobbers with a special sale only available to those who participated. This can be a part of the store promotional strategy which can serve as a powerful marketing tool to attract young and hardto-reach consumers excitingly and effectively (Barnes 2006).
Another attempt to use flash mob as an advertising tool happened when researchers from the Breast Cancer program at the Clarian North Medical Center in Carmel, Indiana, USA organized a flash mob in December 2010 to empower and celebrate cancer survivors (Whiteker 2010).

In the same realm, two senior students from Furman University, South Carolina, USA organized a flash mob in April of 2011 using social media, e.g., the university's Twitter account and Facebook page. The main purpose of the flash mob was to record the event and upload it on YouTube to promote the school spirit and show the school's ties to the community. More than 200 individuals participated in the flash mob including students, faculty, and the school president. This resulted in a successful flash mob that has over 130 thousand views on YouTube as of December 2020 (University 2011; says 2011).

Agnese Vellar in 2012 (Vellar 2012) discussed the use of flash mobs as one of the three grassroots practices that the recording industry uses to promote their music stars. Digital file-sharing caused a crisis to the recording industry, however, due to the nature of the Web 2.0 applications-being audiovisual and participatory-new fans' activities, new types of relationships between fans and pop stars, and new marketing strategies have emerged. Nowadays, fans work as grassroots promoters. In other words, fans of an artist are not only consumers (listening to music) but also, they are promoters of the artist's music or the artists themselves if they feel connected to the artists. For example, they can buy their music records, vote for them to win a competition, or work for free to promote the musician's work. One example of such a group is "Corns". They are the adult female fans of the Chinese pop artist Li Yuchun who work for free to promote "a female artist in a male-dominated entertaining industry" (Vellar 2012). Vellar studied three pop stars, Mengoni (known for "showing the behind-the-scene of his music career"), Lady Gaga (known as a big supporter of LGBT rights), and Shakira (known as being a philanthropist) in her research. She concluded that the record industry can use three different grassroots practices to promote their star. These grassroots promoters can be either street teams who voluntarily work online and offline to promote various activities of an artist such as disseminating stickers and posters of albums or artists in the city's streets, mission participants (or "TSurfers") who get things done and get compensated for their efforts with gadgets, CDs, concert tickets, or opportunities to meet the artists, or music flash mobs promoters who create online video tutorials that teach the audience how to dance to the artist song (Vellar 2012).

In the same year, research has been conducted by Grant et al. (2012) to study the effects of flash mobs on consumer behavior and consumer emotion. These researchers conducted a field study in which an "operatic flash mob" has been organized to examine consumer behavior and emotions 
in a food court in Vancouver's Granville Island Market. They decided to organize an operatic flash mob because many studies show that music affects human mood and invokes emotions. Studies also show that the element of surprise is one of the reasons for flash mobs' success. Due to all these facts, the researchers decided to organize an operatic flash mob. They specifically chose opera as their experiment's music because it's challenging the status quo (and that's what the flash mob intention should be). Their experiment included three different scenarios: first, the shoppers were not exposed to music, second, the shoppers were exposed to recorded music, and finally, the shoppers were exposed to live music with performance as a flash mob. The researchers found that for the "no-music" case the shoppers were very hard to approach (or start a conversation with), for the "recorded music" case many shoppers were complaining about the volume of the music or the music itself. On the other hand, for the "live music" (i.e., the flash mob) case the consumers were very happy (e.g., dancing, singing along, or swaying). The shoppers also wanted to be a part of the flash mob as they felt a heightened sense of connectedness and emotions (Grant et al. 2012).

Grant and Boon in 2013 (Grant and Boon 2013) discussed the consumer reaction toward branded flash obs $^{11}$ as a marketing strategy. More specifically, they used the Persuasion Knowledge Model (Friestad and Wright 1994) to study why certain branded flash mobs succeed (i.e., go viral on YouTube and get a lot of viewership) while others fail (i.e., do not go viral). The researchers focused on the latter case. The Persuasion Knowledge Model is a theoretical model found by Friestad and Wright (1994) to explain how consumers develop knowledge about salespeople strategies to convince them to buy something, hence the consumer cope with this behavior or not (once the persuasion attempt is realized by the consumer). By conducting interviews with three focus groups, the researchers found that flash mobs that are unoriginal, do not stimulate positive emotions, do not show the audience or their engagement, have low production qualities (e.g., the length of the video or the music type), and produced by corporations for visible branding purposes usually fail.

In the same year, Anderson (2013) studied the 2009 Oprah Feelin' commercial flash mob, which was organized as a "surprise" to Opera Winfrey by her show producers to honor her show success as it reached its season 24 . She used "game theory, cognitive studies, and the social and anthropological dimensions" (Anderson 2013) to study the viewership and comments of the online audience who viewed the video of the flash mob on YouTube (Anderson 2013).

\footnotetext{
11 Branded flash mobs are events that are organized by companies to advertise their service, product, etc.
}

Finally, Grant et al. (2015) conducted another research in 2015 to study the effects of branded flash mobs on brand equity. In this research, they did not count only for the viewership of a video on YouTube to determine its success or failure (as in the previous research conducted in 2013) but also analyzed the comments of three successful branded flash mobs' videos to develop "Archetypes of Consumer Attitudes toward Branded Flash Mob Videos Matrix" (Grant et al. 2015) which should help marketing managers organize better-branded flash mobs (Grant et al. 2015). In all the aforementioned research of this subsection, flash mobs have been used in some way or another as a marketing tool.

\subsection{Cultural studies}

A 2010 research conducted by Simone Do Vale (2010) provides a historical review of the Zombie Culture as it was spreading worldwide. He explained how this culture was affected by big global catastrophes such as WWI, the Great Depression, the spread of the HIV pandemic, and terrorist attacks and orchestrated with horror movies and video games. He states that common fears in societies that are broadcasted by constant media messages can be the main reason for flourishing such a culture. After providing a review of this peculiar culture, he compares it to regular flash mobs. He finds that albeit these Zombies' Walks are called Flash Mobs or Zombies Mobs, they have two distinct characteristics from regular flash mobs. First, the walkers do not disperse suddenly as is the case with the flash mobbers. Instead, they mingle with the crowds to form "a lineup of bizarre celebrators" (Do Vale 2010). Second, these walks $d o$ not happen at the same date and time as regular flash mobs do, i.e., they happen asynchronously (Do Vale 2010) (i.e., an example of the long mobs mentioned in (Bylieva 2018)).

In the same year, Gore (Gore 2010) did an ethnographic study to understand the dance flash mobs (also called Dance Mobs) and their effects on the public urban spaces. He analyzed various dance mobs that occurred worldwide and focused on three features of the dance mobs, (1) the site (place), (2) the moves of the dancers, and (3) the scale of the event, which is measured by the number of participants or audience size. Then, he categorized the dance flash mobs into three categories according to their aim, (1) commercial advertisement, (2) political activism, and (3) celebration. Finally, he concluded that regardless of the dance flash mob category they will stick to the memory because of their unusualness, will territorialize spaces that belong to no one to gives space a new meaning and function, and will happen at times that can disturb the usual routines and schedules (Gore 2010).

Another research for the same year, conducted by Brejzek (2010), studied the scenographies created by flash mobs and 
urban swarms ${ }^{12}$ and their utilization of the social network and urban spaces. She found that flash mobs and urban swarms are similar in their use of ubiquitous media, poking fun and surprise at the spectators, and their use of urban space (as a stage for performance). However, the swarms are differing in terms of their self-reflexive narrative which enables their participants to express their impressions and actions while they are performing the swarming action. She concluded that, although flash mobs and urban swarms are organized, directed, and designed using social media, they mesh the virtual and physical spaces of the urban city into social and scenographic spaces, which enable the mobbers to create a dynamic performance that challenges the common behavior of individuals in urban cities, forces the authorities to think about the legality of using these spaces by the networked individuals, and creates a new form of spectatorship (the mobbers are watching themselves and commenting on Twitter or live feeds about their impressions and actions while they were performing their action) (Brejzek 2010).

In her five chapters dissertation published in 2011, Walker (2011) analyzed the performance, rhetoric, culture, and philosophy of flash mobs. She argued that "a flash mob is a new form of performance" (Walker 2011) that affects the creativity, politics, and community of the urban cities in the age of spectacle and surveillance. She started by analyzing the eight flash mobs organized by Bill Wasik and their "unique attributes, actions, and locations" (Walker 2011). She discussed other similar forms of performances (such as Dadaism $^{13}$ and Happenings ${ }^{14}$ ) and their history. Then she focused on Wasik's flash mobs attributes namely: the "agent (the modern hipster), agency (mobile mass communication), and scene (small, enclosed pseudo-public spaces in New York City's post 9/11 society)" (Walker 2011). Finally, she tried to answer a set of "Whys?" questions with regard to Wasik's flash mobs then, concluded that flash mobs are not dead and are not just silly performances or fads that have no meaning, but rather a performance that is conducted by, sometimes, a frustrated society to challenge the common usage of public space or to break the routine of their life. Also, social media is neither good nor bad but a dangerous tool that can be used to recruit, organize, and direct such events (Walker 2011).

In their 2011 case study, Massaro and Mullaney (2011) tried to analyze the aggressive measures taken by Philadelphia officials against gatherings of young people in

\footnotetext{
12 "Derived from flocks of birds or shoals of fish" (Brejzek 2010).

13 Dada is an art movement that started in Europe in the early twentieth century (Trachtman 2006).

14 Happening is an art event that was influenced by Dada. The term was coined in the 1950s by the American artist Allan Kaprow (Wainwright 2019).
}

securitized spaces of Philadelphia between 2009 and 2010 (aka. Philly's Flash Mob Riots). These officials were enforcing curfew zones for those under the age of 18 , monitoring student's cell phones and social media accounts by the FBI, deploying more undercover police officers in potential gatherings locations, convicting more minors with felony charges, etc. By studying the geopolitical and geoeconomic history of the locations in which these flash mobs occurred, the authors found that the use of antiterrorism as a state strategy by Philadelphia's officials was not inaugurated by the September 11 terrorist attack, but more as a result of the historical racial division between the geographically segregated communities in Philadelphia (Massaro and Mullaney 2011).

In the same year, Heverin and Zach (2012) studied the effects of Twitter communications during three US college campus shootings, namely the Johns Hopkins University Hospital shooting, Middle Tennessee State University shooting, and University of Texas Austin shooting, that occurred at the end of 2010 and beginning of 2011. They considered people sharing information during a crisis using a specific hashtag related to the event as a flash mob because they generate a "collective conversation" (Heverin and Zach 2012) that helps an individual make sense of what is going on during a crisis (i.e., collective sense-making ${ }^{15}$ (Heverin and Zach 2012)). So, they used the hashtags \#hopkins, \#mtsu, \#utshooter, and \#utshooting, to collect data for $6 \mathrm{~h}$ during each crisis. This resulted in a total of 7,184 tweets. The authors conducted three types of analysis: content analysis, discourse analysis, and complex time-series analysis. They found that people tend to share more information about the events in the early stages of the crisis while sharing more opinions during the recovery stage of the crisis. They also found that various themes of sense-making emerged during these crises with common patterns. This proves that microblogging communications play an important "role in collective sense-making during" (Heverin and Zach 2012) flash mobs.

In the same realm in 2012, Tonkin et al. (2012) analyzed more than 600,000 tweets and retweets to study how Twitter was used during the 2011 London Riots. Data were collected from Twitter using two hashtags: \#LondonRiot and \#RiotCleanup, from August 9 to August 11, 2011. The authors analyzed the data to identify prominent topics, actionable URLs, and other media types. They found little evidence of Twitter being used as an organizational tool to promote illegal actions during the London Riots. These tweets would

\footnotetext{
$\overline{15}$ Sense-making is a process in which humans go through to seek information that will help him/her in understanding what is going on in the world surrounding them or in other words fill their cognitive gaps (Heverin and Zach 2012).
} 
either die out without being retweeted or retweeted to shame the tweet's creator (Tonkin et al. 2012).

In the same year, Mitchell and Oswald (Mitchell and Boyod 2012) discussed the use of flash mob as a tactic to push political agendas. For example, in 2011 during the Belarus protests, a group of people gathered in a public place and started to clap their hands in unison. This act resulted in various arrests by the police that showed the police brutality as they arrested people just for a simple act of clapping their hands. After providing various examples of flash mobs being used as political tactics, they concluded that political flash mobs will flourish in the future and can be powerful tools for effective collective action.

In 2013, Shresthova (2013) studied the Chhatrapati Shivaji Terminus (CST) train station Bollywood Dance Flash Mob to understand when and how popular culture fandom, e.g., Bollywood dance, might support political action. Such flash mobs are organized using the new digital communication technologies, e.g., social media, mobile communication, and in-person rehearsal. She found that the CST flash mob that took place in November 2011 was politically interpreted as a result of the organizers' choice of music, location, and dance. The music was taken from a famous Indian movie in which a group of people fought the corruption in the Indian government. The chosen choreography "supported a symbiotic relationship between the film and the CST flash mob" (Shresthova 2013). Finally, the flash mob took place at the same location where one of the terrorist attacks happened in Mumbai in 2008. Even though the flash mob organizers wanted a pure and fun event, it was still interpreted as a political action and led to various reactions online and offline (Shresthova 2013).

In the same year, Houston et al. (2013) studied the urban youth's perspectives on flash mobs to understand their motivation to participate, the causes and consequences they think they might face, and the possible solutions to avoid violent flash mobs. They surveyed a focus group that consists of 50 participants from Kansas City, Missouri because it was the place of a recent violent flash mob where youth were the primary participants (or the participant's peers). They found that youth violent flash mobs are usually caused by youth boredom and youth wanting to: gain attention, see each other, watch fights, and be visible or recognized (some assertion of identity). They also found that providing youths with more safe and fun activities, improving the various city and community services, more police presence in existing events, and trying to fix the social disorder in the community, in general, could help in mitigating the youth violent flash mobs (Houston et al. 2013).

In the same realm in 2014, Molnár (2014) studied flash mobs and their effects on the contemporary urban youth culture. In her study, she compares flash mobs to other forms of urban pranksterism and states that there are strong affinities between flash mobs and other movements. As an analogy, flash mobs are similar to the Dadaism and Surrealism movements (which appeared at the beginning of the twentieth century) or some of the students' movements such as the Spassguerilla, the Yippies,${ }^{16}$ or the Orange Alternative in terms of their organizational structure, their use of the media, their accusations of being pointless, and their tactical repertoire. However, they are different in terms of their usage of the physical space, cultural and political intent, and ease of organizing (due to modern communication technologies). After analyzing more than 200 different flash mobs (between 2003 and 2009) and categorizing them into five different categories based on their intent she found that a flash mob is an urban phenomenon/practice that has been positively impacted by mobile communication technologies and it constitutes a powerful tool that can affect our experience of the urban space while nurturing new forms of sociability (Molnár 2014).

In 2015 Yiming (2015) studied flash mobs and their effects on the Chinese urban city culture and space. They also compared the "Chinese-style" flash mobs to other Western flash mobs. They found that even though the first flash mob happened in 2003 in the USA (organized by Bill Wasik), the flash mob phenomenon was not introduced to China until 2008. From 2010 to 2012, flash mobs flourished in China, and they were different in nature than the traditional Western flash mobs as they were more acting "as a means of public welfare and marketing" (Yiming 2015). The authors argue that flash mobs occur in urban cities because of the urban people's mental tiredness that is caused by their busy routine life. Those people still want to communicate (non-virtually) with someone or meet physically with someone, hence flash mobs occur as comforting mechanisms to ease the pressure of their life and give them excitement. For example, many flash mobs occur during the Chinese Spring Transportation Season ${ }^{17}$ in train stations which helps in breaking the psychological patterns at train stations and ease the travelers' hassles caused by waiting, anxiety, ignorance, and exhaustion. They also argue that flash mobs usually occur in meaningless places within the city such as city squares, transportation hubs, open spaces, or shopping centers, to break the usual tradition of "do not talk to strangers" (Yiming 2015) hence, flash mobs affect the spatial and cultural constructions of the city.

In the same year, Tsou (2015) discussed the phenomena of Human Flesh Search and how it has the same tactics

\footnotetext{
16 The Youth International Party (Yippie) is a group of people who invented various forms of playful protests in the late 1960s against the Vietnam War (Gore 2010).

17 The 40 days season in which millions of Chinese citizens worldwide travel back to China to celebrate the Lunar New Year with their families as part of their culture (Yiming 2015).
} 
and mechanics as the Smart Flash Mob phenomenon. She emphasizes that these "Digital Natives" are not always the "good guys" who strive to make a change for the better. When the voices of many become one, it can be dangerous. Even though we might think we are on the "right" side, it is hard to believe that we are not going to end up being on the other side. The Human Flesh Search or "Renrou Sousuo" is an event in which individuals are recruited online or offline to identify immoral individuals and socially punish them (by making their identity exposed which can cause them many problems such as death threats, losing their job, having to run out of town) because the law did not count their immoral act as a crime. This phenomenon started in 2001 in China when a netizen told a lie about the Hong Kong actress Ziyao Chen, but it became popular in 2006 when a kitten-killer posted a video of a girl killing a cat with her stilettos. Even though such a phenomenon can help authorities as is the case of the 2019 documentary by Netflix "Don't F**k With Cats: Hunting an Internet Killer" (Lewis 2019) in which a group of people worked very hard across multi-countries using social media to identify the cat killer (who also turned out to be a serial killer) and brought him to justice, it can still in many cases lead to unjust punishments to individuals as it does not involve a trial and goes directly to punishment (Tsou 2015). All the pieces of research mentioned in this subsection studied flash mobs as a cultural phenomenon and their effect on the social life, physical space, culture, politics, and youth of the urban cities.

\subsection{Law}

In 2012, Steinblatt (2011) conducted a study that focuses on the laws and regulations that can be posed against the people who organize and participate in flash mobs that lead to violence, security threats, and crimes. After reviewing various violent flash mobs and the authorities' responses to each and reviewing various lawsuits related to freedom of speech (e.g., Dennis v. the United States or Schenck v. the United States), she concluded that the government needs to

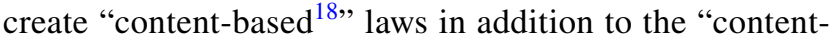
neutral" laws (e.g., permit requirements and youth curfews) to regulate digital speech that incites flash mobs. These laws must be targeted toward the organizers of the events and must be evaluated under the Brandenburg test ${ }^{19}$ to guarantee

\footnotetext{
18 Content-based laws discriminate "against speech based on the substance of what it communicates" while content-neutral laws "applies to expression without regard to its substance" (Hudson 2009).

19 Brandenburg test was established in 1969 as a result of the Brandenburg (a leader of a Ku Klux Klan group) v. Ohio case, which prevent the government from punishing inflammatory speech unless that speech is "directed to inciting or producing imminent lawless action and is likely to incite or produce such action" (Legal Information Institute 2021a, b).
}

that these laws do not violate the freedom of speech right granted by the First Amendment (Steinblatt 2011).

In the same realm in 2013, Fitzpatrick (2013) took the Bay Area Rapid Transit (BART) wireless network shutdown on August 1, 2011, as his case study to investigate the constitutionality of regulating flash mobbers' use of social media to recruit and organize flash mobs or to evade authorities. After reviewing various laws, that are resulted from various lawsuits, and addressing various arguments made by procensorship (of social media use by flash mobbers) and anticensorship groups, he concluded that the legality of flash mobbers use of social media must be evaluated case-by-case basis because completely restricting the use of social media by flash mobbers, in many cases, will violate the freedom of speech protected by the First Amendment as was the case in the "BART's wireless network shutdown" (Fitzpatrick 2013). All the pieces of research mentioned in this subsection discussed the legality of organizing flash mobs and the consequences that flash mobbers should face in case of organizing violent flash mobs.

\section{Findings}

In this section, we summarize our findings and address the research questions we mentioned in our introduction.

In this research, we try to create a typology for flash mobs by reviewing various scholarly articles. This classificatory study reveals that even though flash mobs have been used or studied in various disciplines, there is still sporadic literature (most of the articles were published between 2005 and 2019 with two peaks in 2011 and 2015) especially, the ones that focus on the computational aspect of flash mobs. In our previous works, we studied various flash mobs using the theory of collective action (Coleman 2017) to understand their formation, model the power that flash mobbers might exert on the outcome of the event (Al-khateeb and Agarwal 2014a), and the choices flash mobbers might face with regards to participating in flash mobs or not (Al-khateeb and Agarwal 2014b, 2015b). We also tried to operationalize our model using a real-world case study (Al-khateeb and Agarwal 2015a). In addition to that, we tried to understand the threats that flash mobs pose to smart city and urban planning policymaking (Alassad et al. 2019), the flash mobs that spread COVID-19 conspiracy theories (Alassad et al. 2021a), and the various flash mobs that spread adversarial information operations (Alassad et al. 2021b). However, the literature lacks similar attempts. This typology is important because it encapsulates various existing literature and puts forward all the various types of flash mobs into categories to eliminate any possible ambiguities. 


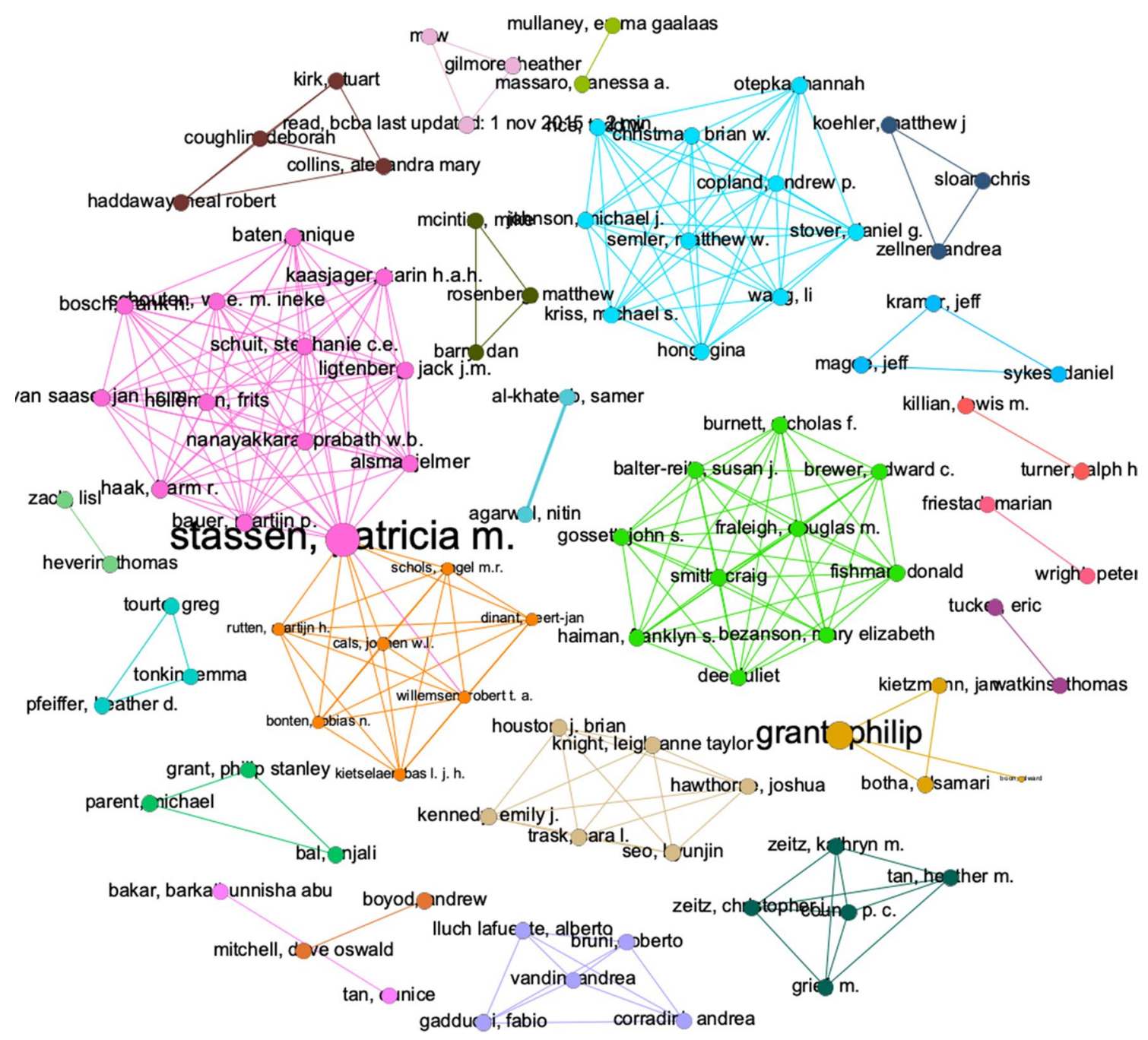

Fig. 2 Co-authors network of our selected bibliography

In addition to that, we posit a need to analyze the coauthors' network of our selected bibliography to identify communities of researchers interested in studying various flash mob events. Hence, we decided to conduct a co-authors network analysis. The network in Fig. 2 is a co-author undirected network or, in other words, an author-by-author network between the co-authors of the articles in our bibliography. The edge weight signifies the number of times two authors have collaborated on multiple papers. The node size signifies the PageRank (Brin and Page 1998) of a node (how important a node is based on its neighbor's importance). The network contains 135 nodes (authors) with 267 edges. We eliminated isolates, i.e., nodes that are not connected to any other nodes (single author papers), to make the graph more visible. This resulted in a network that contains 98 nodes and 267 edges. We ran a modularity-based community detection algorithm (Blondel et al. 2008; Lambiotte et al. 2008) to find clusters of authors. This resulted in 23 communities which signify the collaboration between various authors in publishing a paper between 2005 and 2019. From this coauthor network, we can identify the most productive and best-connected authors (i.e., has the strongest co-authorship relations). It also helps us identify important authors based on the strength of their relations. We observe few cliquelike communities of authors who collaborate (intra-group collaboration), but not many communities collaborated with other communities (rare inter-group collaboration). This led us to the proposition that more inter-group collaboration is needed to have a better understanding of this phenomenon.

To address the first research question (RQ1: How is the term "Flash Mob" used in the literature? What themes or topics it appears at?), we reviewed and analyzed 33 research articles and grouped them into seven groups based on the common topic or discipline they are from. Most of the flash mobs research came from cultural studies, which view flash 


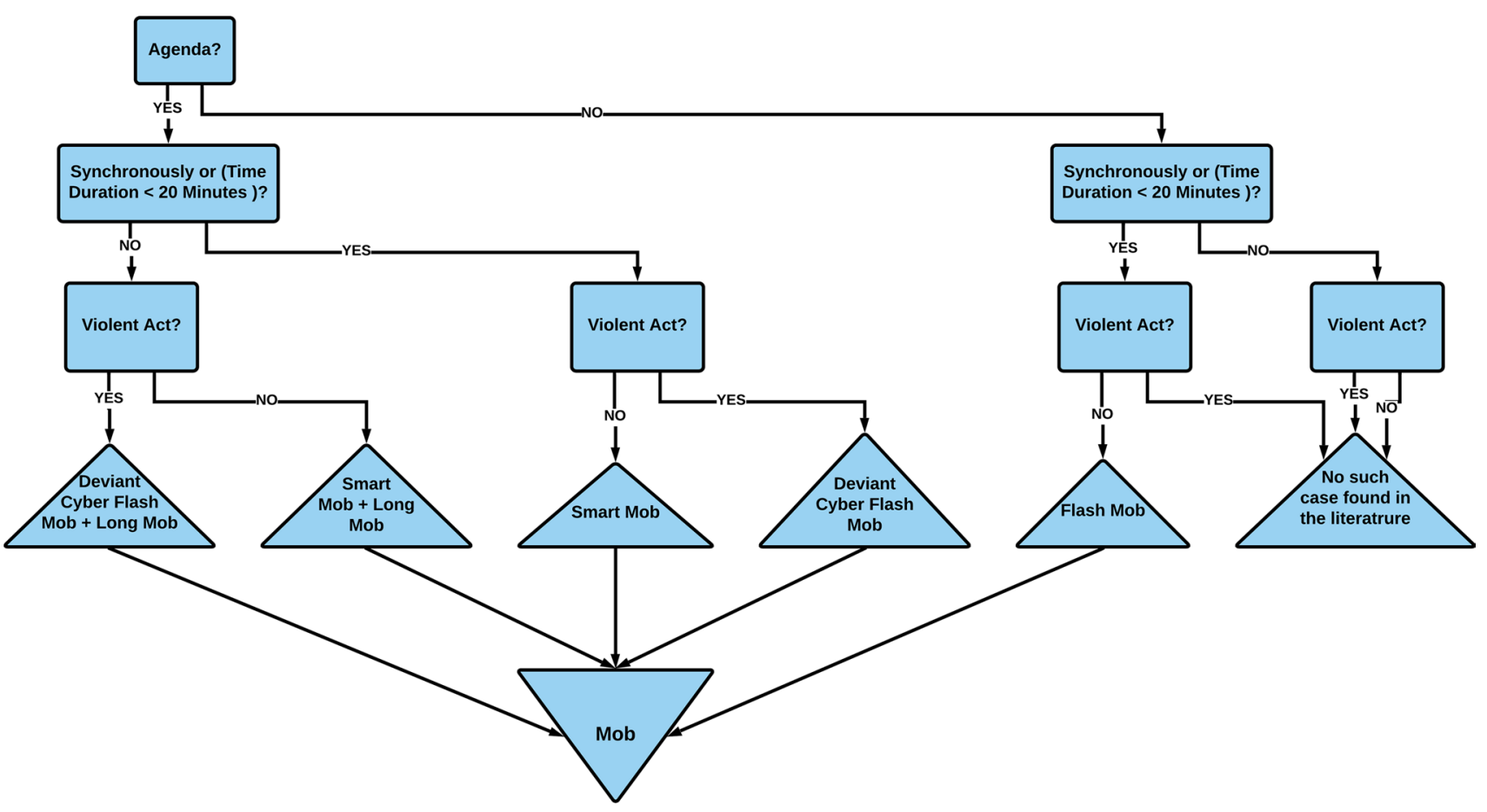

Fig. 3 All the Mob subcategories found in the literature categorized based on our three factors: agenda, synchronicity, and the existence of violent acts

mobs as a cultural phenomenon that has effects on the social life, physical space, culture of the city, politics, and youth life in the urban cities. The second topic was marketing, which highlighted the use of flash mobs in some way or another as a marketing tool. The number of articles per topic is as follows: Cultural Studies (13 articles), Marketing (8 articles), Communication Studies (3 articles), Biomedical research (3 articles), Education (3 articles), Law (2 articles), Software (1 article) which proves the lack of flash mob research in some of these disciplines (e.g., Law or Software), but also highlight the opportunity to do more research in the aforementioned disciplines.

To address the second set of research questions (RQ2: What are the different forms of flash mobs studied in the literature? What are the common and most agreedupon properties that define each of these forms? Can we categorize them based on their common properties?), We found that the flash mob phenomenon, which was studied in various articles, was referred to as "flash mob" (Mitchell and Boyod 2012), "classic mob" (Bylieva 2018) (Molnár 2014), "virtuous mob" (Shapiro 2017), "political mob" (Walker 2011), "smart mob" (Tsou 2015), "criminal flash mob" (Steinblatt 2011), or other names. In many cases, they either meant the same thing or in many other cases they meant different things, i.e., the global diffusion of flash mobs has diluted their original meaning. We also did not find any research article that talks about the distinctive characteristics of these different forms of flash mobs. Hence, after reviewing the literature we propose the term "Mob" to be the root term so we can categorize its various forms (branches) and eliminate ambiguities. We define the root term "Mob" as an event that is organized via social media, emails, SMS, or other forms of digital communication technologies in which a group of people (who might have an agenda or not) get together online or offline to collectively do something then disperse (quickly or over a longer period of time). Below, we provide a hierarchical classification (also illustrated in Fig. 3) of the various terms found in the literature and how they associate with the with the term "flash mob". The term flash mob was used to refer to two distinct types of events:

(1) Classic Flash Mob, Regular Flash Mob, Traditional Flash Mob, Virtuous Flash Mob, Swarming Art (Nicholson 2005), Guerilla Art (Nicholson 2005), Urban Swarm (Brejzek 2010), or just Flash Mob: these are the events visioned by Bill Wasik when he first organized the first flash mob. This subcategory of events must have the following properties: (1) no particular issue or mandate or agenda, (2) happen in public places (popular in large cities), (3) participants perform random acts, (4) have the surprise element (known only to participants so others will be shocked), (5) have no leader, (6) do not include violent acts, and (7) should 
Fig. 4 Our mob categorization based on our literature review findings

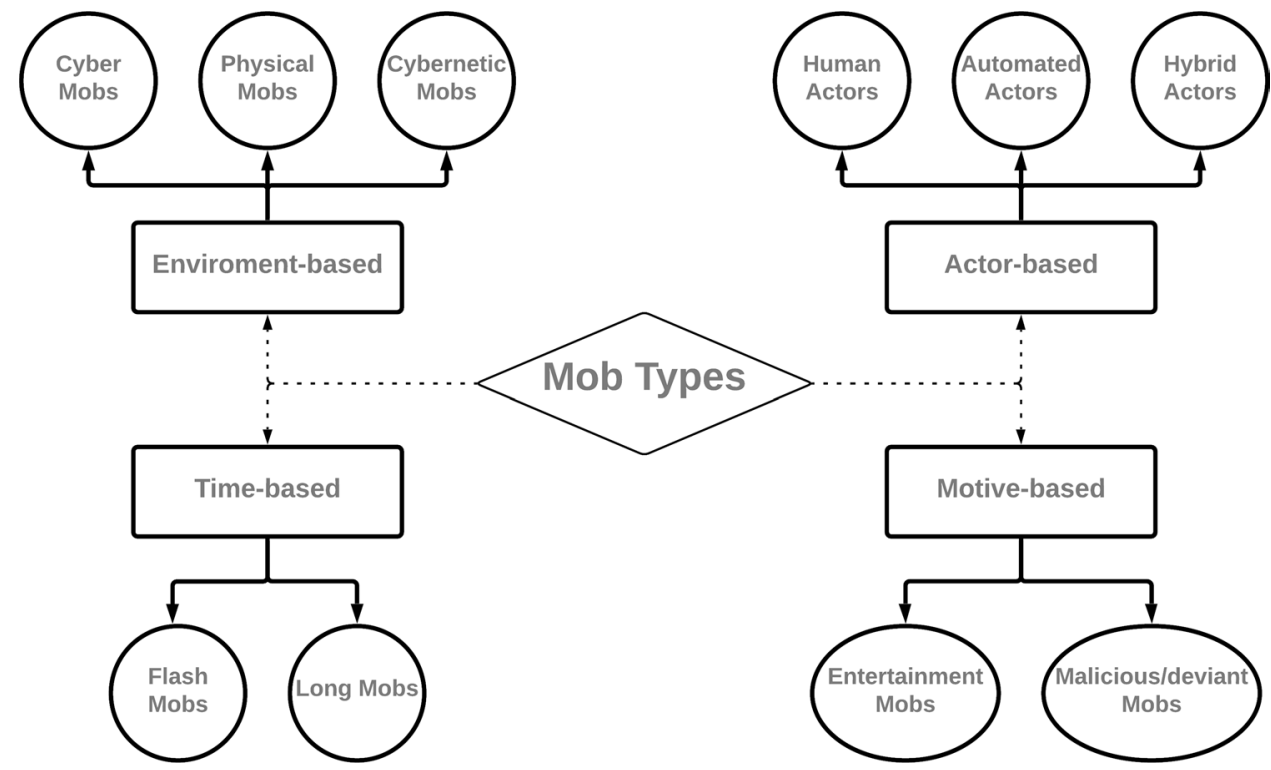

e.g., the Arab Spring in 2010. Other names of mobs that fall under the Smart mobs' category include:

example, the two categories of flash mobs Atomized Flash Mobs ${ }^{20}$ and Interactive Flash Mobs ${ }^{21}$ identified by Molnár (2014) would fit under this category of the mob.

(2) Smart mobs: these are the events visioned by Howard Rheingold, in his book "Smart Mobs: The Next Social Revolution" (Rheingold 2002), i.e., events that have an agenda that can be political, sociological, economic, commercial, or religious. For example, the Performance Flash Mobs, ${ }^{22}$ Political Flash Mobs, ${ }^{23}$ and Advertising or Commercial or Branded Flash Mobs $^{24}$ identified by Molnár (2014) would fit under this category of the mob. Smart mobs also should benefit a group of people (i.e., there should be some utility gained by participating beyond just the fun part) (Nicholson 2005) and can last for more than 20 min,

\footnotetext{
${ }^{20}$ Atomized Flash Mob: a group performs the same activity, does not interact with each other, has no political intent, and disperse within 10 min (Molnár 2014).

${ }^{21}$ Interactive Flash Mob: a group in which participants interact with each other and usually last for more than 10 min disrupting urban public spaces (Molnár 2014).

${ }^{22}$ Performance Flash Mob: a group that has a stated artistic intent (e.g., to promote performance, an exhibition, or an artist), performs in outdoor spaces, and consists of a large group of strangers as opposed to a few artists in the role of professional provocateurs (Molnár 2014).

${ }^{23}$ Political Flash Mob: a group gathers in a specific place to make a political point but without protesting, it is different than the smart mob in that it adopts guerilla-type tactics and an element of absurdity, e.g., gathering in a place and eating and eating ice cream in front of the police (Molnár 2014)

${ }^{24}$ Advertising Flash Mob: a group staged by professional advertising agencies perform in quasi-public commercial spaces such as shopping malls to promote a company, a service, or a product (Molnár 2014).
}

- Deviant Cyber Flash Mobs (Al-khateeb and Agarwal 2019) or Vicious Flash Mobs (Shapiro 2017): These are smart mobs (with agenda) and include deviant acts. For example, the Violent Youth Flash Mobs (Houston et al. 2013), Criminal Flash Mobs (Steinblatt 2011), Flash Robs (Bylieva 2018; Steinblatt 2011), and Rolezinho (Bylieva 2018) would fit under this category of mobs.

- Long-Mobs such as the Internet mobs, I-mobs, or Virtual Flash Mobs: These are the events in which people do the same action but not coincide in time, i.e., asynchronously (i.e., last more than $20 \mathrm{~min}$ ) and mostly happens in the cyberspace (not always though), for example, the Virtual Flash Mobs (Bylieva 2018) are events in which participants are required to write some text, post a picture, press like button, retweet, answer a specific question, etc., using a specific hashtag. These events do not have to happen all at once, and can last for a month or more such as the Zombies Mobs (Do Vale 2010), the Ice Bucket Challenge in 2014, or Human Flesh Search ${ }^{25}$ aka "Renrou Sousuo" (Tsou 2015).

\footnotetext{
${ }^{25}$ Renrou Sousuo: is an event that started in 2001 in China in which individuals are recruited online or offline to identify non-moral individuals and try to punish them (usually by exposing their identity) because the law did not count their non-moral act as a crime (Tsou 2015).
} 


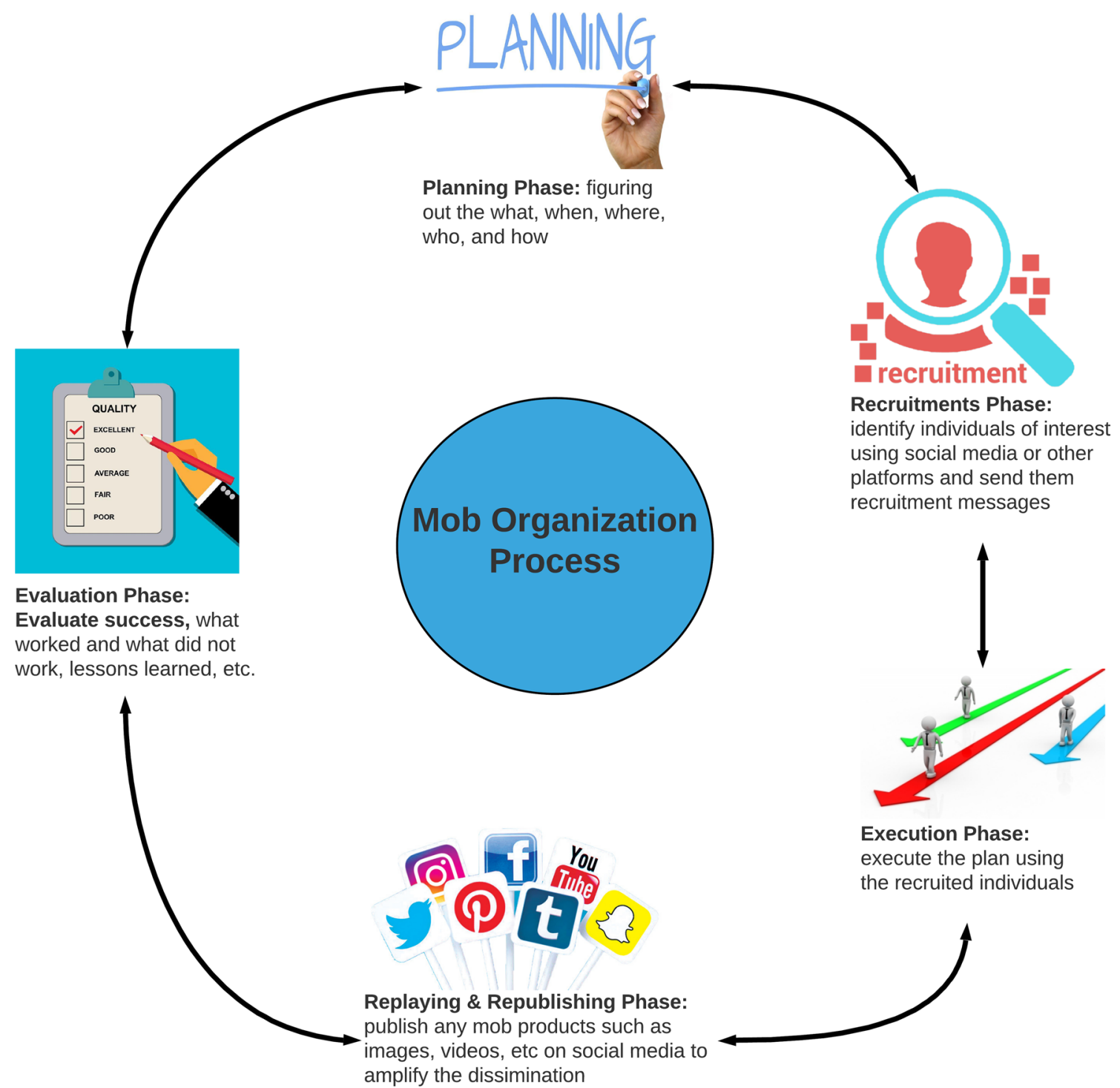

Fig. 5 The mob organization process

Figure 3 shows a decision tree view that uses the three factors we found in the literature, i.e., agenda, synchronicity, and the existence of violent acts that seem to distinguish the subcategories of our root term, i.e., Mob (which is shown at the bottom of the figure to indicate that all these various subcategories are part of our proposed term). Using these findings, we can categorize mobs in general into four main non-exclusive categories. These mob non-exclusive categories can be based on the acting environment, actors' type, length of the mob, and the motive of the mobbers. Figure 4 shows our four main categories and subcategories. It's worth noting that the term "crowd" refers to "an organized event occurring within a defined space, which is attended by a large number of people... not dependent on the reason for the gathering" (Zeitz et al. 2009).

To address the third set of research questions (RQ3: Is the "flash mob" phenomenon dead as it was claimed by its creator or is it still alive? are there some organizations that still organize flash mobs?), We found that in addition to the aforementioned forms of flash mobs, various websites function as clearinghouses for flash mob organizers and practitioners by offering information on upcoming flash mob events. "Appendix" section contains a list of organization websites that were mentioned in the literature and indicates their working condition. 
The list shown in "Appendix" section proves that there are still organizations that organize flash mobs ( 8 out of the 14 URLs mentioned in the literature still work and have a lot of information about upcoming or recurring mobs) and the flash mob phenomenon is not dead yet. Also, these URLs serve as a good starting point for researchers interested in collecting data about flash mobs: time, location, the goal of the event, etc. In addition to that, they can guide the researcher to the right place to collect more data about a specific mob, for example, if a mob is advertised on one of these websites and have a Facebook page or a Twitter account, then the researcher can leverage this information by collecting data from that social media outlet to analyze the mob. Cyber commentaries on YouTube and Facebook pages are usually written by supporters and/or participants of flash mobs while blogs and online news sources attract "more heterogeneous readership and offer a glimpse of strong criticism that is also directed at flash mobs" (Molnár 2014). So, the more diverse the collected data is (diverse in terms of the data sources and audiences), the better the analysis would be.

We also found that the mob organization process (see Fig. 5) includes the planning phase, the recruitments phase, the execution phase, the replaying and republishing of the products of the flash mob phase such as a retweet on Twitter, a Facebook post, or a YouTube Video (Zellner et al. 2011), and the evaluation phase where the mob organizers evaluate what worked and what did not, lessons learned, etc. In many of the scholarly articles we reviewed about this topic, the organizers of the mob cared so much about posting the mob's video online and mostly on YouTube (i.e., the replaying and republishing phase). Some of them even considered recording the flash mob and posting it on YouTube more important than the flash mob itself because it gives the people the re-view capability which is not possible without recording and posting online (Venning 2012). As Lissa Soep has called it the "digital afterlife" (Soep 2012) which has a significant "potential for a reaction and recontextualization by other users" (Soep 2012). Hence, we posit a need to study mobs on YouTube. There are many mob videos posted on YouTube (a quick Internet search on YouTube returns more than 5,910,000 hits as of December 28, 2020) of flash mob videos) that can easily be identified. Then data collection and analysis can be conducted to understand the viewers' behavior toward the various mob categories.

\section{Limitations}

The primary limitation of our research comes from the methodology we used. We selected three search engines, i.e., Google Scholar, IEEE Xplore, and the ACM Digital Library to pick our articles. We are aware that we might have missed few valuable works done by other researchers in this field. Also, we might have reviewed articles from specific researchers more than others due to the results returned by our selected search engine algorithms. However, the point of this review is to capture a snapshot of the major themes in the literature on flash mobs and to address the research questions mentioned above (i.e., not to study all the existing literature as this would be a daunting task). We also want to provide researchers in this field a literature summary with strong findings that, hopefully, help them in their future studies. We posit that our search engines return trustworthy resources, e.g., Google Scholar should return trustworthy resources in its first few pages of the search results as suggested in (Haddaway et al. 2015).

\section{Conclusion and future research directions}

In this summative, chronological, and by topic literature review article, we first explored the disciplines that used the term flash mob and uncovered its meaning. We found that many scholarly articles talked about the history of flash mobs, their effects on urban life, the effects of the new forms of communication technologies on flash mob organization and popularization, the ways to use flash mobs to educate, conduct research, or build software, etc. However, we did not find any attempt to computationally model, find, or predict flash mobs' occurrences. Unfortunately, we do not live in a cyber-utopia. Flash mobs, which are meant to be fun social experiments, took various forms as time passed and recently, they involved deviant acts. We found many scholarly articles that mentioned the deviant aspect of flash mobs, however, very few attempts to actually study, analyze, or model these events exist. Second, we investigated the various forms of flash mob and propose a root term, i.e., $M o b$ to categorize its various forms and eliminate ambiguities. Finally, we prove that this phenomenon still exists by investigating various URLs, mentioned in the literature, of organizations that function as clearinghouses for flash mob organizers and practitioners by offering information on upcoming mobs.

We also found, in many articles, that what defines the outcomes of the flash mobs are the profound ambiguity of the event, the resulting spontaneous reactions, the emotions felt by spectators, and the behaviors of the participants and audience (Tan and Bakar 2015). Many pieces of research state that viewers who feel a strong emotion (supportive emotion) toward a video are more likely to share it than viewers who feel no emotion or antagonistic emotion. No research has been conducted to validate this, so a possible future research direction could be studying the relationship between the tweet sentiments and the retweet count OR the relationship between comments sentiments and video views count. More specifically, we can try to find an answer for the 
following research question: can we use sentiment analysis during flash mobs as an indicator to predict the flash mob result? more specifically, can we use positive sentiments as an indicator of a flash mob success while negative sentiments as an indicator of a flash mob failure?

Another future research direction could be to conduct a comprehensive study that documents various cases of successful and fails flash mobs along with their properties, e.g., time, location, number of participants, number of recruiters, etc. as there is a lack of such a study in the literature we reviewed. Finally, many researchers talked about the effect of grassroots promoters or powerful actors or ambassadors, but no research tried to quantify the power or effect of these actors on the mob's success or failure.

\section{Appendix}

Below, we are listing the organization websites we found mentioned in the literature and indicate whether they are currently working or not:

- http://www.flashmobamerica.com/ (works as of January $25,2021)$

- http://www.cheesebikini.com/ (works as of January 25, 2021)

- https://thedemlabs.org (works as of January 25, 2021)

- https://improveverywhere.com/ (works as of January 25, 2021)

- http://www.newmindspace.com/ (works as of January 25, 2021)

- https://flashmob.co.uk/ (works as of January 25, 2021)

- www.smartmobs.com (works as of January 25, 2021)

- www.die-urbanauten.de (works as of January 25, 2021)

- flashmob.com (does not work as of January 25, 2021)

- flashmob.info.com (does not work as of January 25, 2021)

- theflashmob.ca (does not work as of January 25, 2021)

- http://www.satanslaundromat.com/ (does not work as of January 25, 2021)

- http://www.flashmobroma.it/ (does not work as of January $25,2021)$

- http://urbanpranksternetwork.com/ (does not work as of January 25, 2021)

Acknowledgements This work is funded in part by the Center for Undergraduate Research and Scholarship (CURAS) at Creighton University, U.S. National Science Foundation (OIA-1946391, OIA1920920, IIS-1636933, ACI-1429160, and IIS-1110868), U.S. Office of Naval Research (N00014-17-1-2675, N00014-17-1-2605, N6833519-C-0359, N00014-19-1-2336, N68335-20-C-0540), U.S. Air Force
Research Lab, U.S. Army Research Office (W911NF-20-1-0262, W911NF-16-1-0189), U.S. Defense Advanced Research Projects Agency (W31P4Q-17-C-0059), Arkansas Research Alliance, the Jerry L. Maulden/Entergy Endowment at the University of Arkansas at Little Rock, and the Australian Department of Defense Strategic Policy Grants Program (SPGP) (award number: 2020-106-094). Any opinions, findings, and conclusions, or recommendations expressed in this material are those of the authors and do not necessarily reflect the views of the funding organizations. The researchers gratefully acknowledge the generous support.

Funding This research is funded in part by the Center for Undergraduate Research and Scholarship (CURAS) at Creighton University. U.S. National Science Foundation (OIA-1946391, OIA-1920920, IIS-1636933, ACI-1429160, and IIS-1110868), U.S. Office of Naval Research (N00014-17-1-2675, N00014-17-1-2605, N6833519-C-0359, N00014-19-1-2336, N68335-20-C-0540), U.S. Air Force Research Lab, U.S. Army Research Office (W911NF-20-1-0262, W911NF-16-1-0189), U.S. Defense Advanced Research Projects Agency (W31P4Q-17-C-0059), Arkansas Research Alliance, the Jerry L. Maulden/Entergy Endowment at the University of Arkansas at Little Rock, and the Australian Department of Defense Strategic Policy Grants Program (SPGP) (award number: 2020-106-094). Any opinions, findings, and conclusions or recommendations expressed in this material are those of the authors and do not necessarily reflect the views of the funding organizations. The researchers gratefully acknowledge the support.

Availability of data and material Not applicable.

Code availability Not applicable.

\section{Declarations}

Conflict of interest Not applicable.

\section{References}

Alassad M, Hussain MN, Agarwal N (2021a) Comprehensive decomposition optimization method for locating key sets of commenters spreading conspiracy theory in complex social networks. CEJOR. https://doi.org/10.1007/s10100-021-00738-5

Alassad M, Spann B, Agarwal N (2021b) Combining advanced computational social science and graph theoretic techniques to reveal adversarial information operations. Inform Process Manag 58(1): 102385

Alassad M, Spann B, Al-khateeb S, Agarwal N (2019) Using computational social science techniques to identify coordinated cyber threats to smart city networks. In: Joint international conference on design and construction of smart city components, pp 316-26. Springer

Al-khateeb S, Agarwal N (2014a) Developing a conceptual framework for modeling deviant cyber flash mob: a socio-computational approach leveraging hypergraph constructs. J Digit Forensics Secur Law 9(2):10

Al-khateeb S, Agarwal N (2014b) Modeling flash mobs in cybernetic space: evaluating threats of emerging socio-technical behaviors to human security. In: 2014 IEEE joint intelligence and security informatics conference, pp 328-328. IEEE

Al-khateeb S, Agarwal N (2015a) Analyzing deviant cyber flash mobs of Isil on Twitter. In: International conference on social 
computing, behavioral-cultural modeling, and prediction, pp 251-57. Springer

Al-khateeb S, Agarwal N (2015b) Analyzing flash mobs in cybernetic space and the imminent security threats a collective action based theoretical perspective on emerging sociotechnical behaviors. In: 2015 AAAI spring symposium series

Al-khateeb S, Agarwal N (2019) Deviance in social media. In: Deviance in social media and social cyber forensics, pp 1-26. Springer

Alsma J, van Saase JLCM, Nanayakkara PWB, Schouten WEMI, Baten A, Bauer MP, Holleman F et al (2017) The power of flash mob research conducting a nationwide observational clinical study on capillary refill time in a single day. Chest 151(5):11061113. https://doi.org/10.1016/j.chest.2016.11.035

Anderson ME (2013) Oprah Feelin': technologies of reception in the commercial flash mob. In: McCutcheon JR, Sellers-Young B (eds) Embodied consciousness. Palgrave Macmillan, London, pp 159-176. https://doi.org/10.1057/9781137320056_12

Barnes NG (2006) Mob it and sell it: creating marketing opportunity through the replication of flash mobs. Mark Manag $\mathrm{J}$ 16(1):1-268

Barry D, McIntire M, Rosenberg M (2021) Our President Wants Us Here': the mob that stormed the capitol. The New York Times, January 9, 2021, sec. U.S. https://www.nytimes.com/2021/01/09/ us/capitol-rioters.html

Blondel VD, Guillaume J-L, Lambiotte R (2008) E Lefebvre (2008) Fast unfolding of communities in large networks. J Stat Mech Theory Exp 10:P10008

Brejzek T (2010) From social network to urban intervention: on the scenographies of flash mobs and urban swarms. Int J Perform Arts Digit Med 6(1):109-122

Brignall M (2021) How GameStop traders fired the first shots in Millennials' war on Wall Street. The Guardian. January 30, 2021. http://www.theguardian.com/business/2021/jan/30/how-games top-traders-fired-the-first-shots-in-millenials-war-on-wall-street

Brin S, Page L (1998) The anatomy of a large-scale hypertextual web search engine. Comput Netw ISDN Syst 30(1-7):107-117. https:// doi.org/10.1016/S0169-7552(98)00110-X

Bruni R, Corradini A, Gadducci F, Lafuente AL, Vandin A (2015) Modelling and analyzing adaptive self-assembly strategies with Maude. In: Science of computer programming, selected papers from the ninth international workshop on rewriting logic and its applications (WRLA 2012), vol 99(March), pp 75-94. https://doi. org/10.1016/j.scico.2013.11.043

Bylieva DS (2018) Evolution of smart mob: from flash mob to smart city element, pp 225-35. https://doi.org/10.15405/epsbs.2018.02. 26

Coleman JS (2017) Mathematics of collective action. Transaction Publishers

Do Vale S (2010) Trash mob: zombie walks and the positivity of monsters in western popular culture. In: The domination of fear, pp 191-202. Brill Rodopi

Daily Express Newspaper (2010) Flash mob ‘drop dead' in anti-nuclear ad campaign. Express.Co.Uk. May 28, 2010. https://www.expre ss.co.uk/news/weird/177780/Flash-mob-drop-dead-in-anti-nucle ar-ad-campaign

Fitzpatrick MJ (2013) The constitutionality of restricting the use of social media: flash mob protests warrant first amendment protections. Seton Hall Law Rev 43:43

Friestad M, Wright P (1994) The persuasion knowledge model: how people cope with persuasion attempts. J Consum Res 21(1):1-31

Gilmore H, MSW, BCBA Last updated: 1 Nov $2015 \sim 2$ min read (2015) BCBA exam study topics: measurement \& interobserver agreement. November 2, 2015. https://pro.psychcentral.com/childtherapist/2015/11/bcba-exam-study-topics-measurement-inter observer-agreement/, https://pro.psychcentral.com/child-thera pist/2015/11/bcba-exam-study-topics-measurement-interobser ver-agreement/

"Google Trends" (2006) Search engine. Google Trends. May 11, 2006. https://trends.google.com/trends/?geo=US

"Google Trends" (2021) In Wikipedia. Wikipedia. https://en.wikipedia. org/w/index.php?title=Google_Trends\&oldid=999727797

Gore G (2010) Flash mob dance and the territorialisation of urban movement. Anthropol Noteb 7:125-131

Grant P, Boon E (2013) When the persuasion attempt fails-an examination of consumers' perception of branded flash mobs: when the persuasion attempt fails-branded flash mobs. J Public Aff 13(2):190-201. https://doi.org/10.1002/pa.1474

Grant P, Botha E, Kietzmann J (2015) Branded flash mobs: moving toward a deeper understanding of consumers' responses to video advertising. J Interact Advert 15(1):28-42. https://doi.org/10. 1080/15252019.2015.1013229

Grant PS, Bal A, Parent M (2012) Operatic flash mob: consumer arousal, connectedness and emotion: effects of operatic flash mobs on the consumer. J Consum Behav 11(3):244-251. https://doi.org/ $10.1002 / \mathrm{cb} .384$

Haddaway NR, Collins AM, Coughlin D, Kirk S (2015) The role of google scholar in evidence reviews and its applicability to grey literature searching. PLoS ONE 10(9):e0138237

Heverin T, Zach L (2012) Use of microblogging for collective sensemaking during violent crises: a study of three campus shootings. J Am Soc Inform Sci Technol 63(1):34-47. https://doi.org/10. 1002/asi.21685

Houston JB, Seo H, Knight LAT, Kennedy EJ, Hawthorne J, Trask SL (2013) Urban youth's perspectives on flash mobs. J Appl Commun Res 41(3):236-252. https://doi.org/10.1080/00909882.2013. 825728

Hudson DL (2009) Content based. University website. The Free Speech Center: First Amendment News and Insights from MTSU. https:// www.mtsu.edu/first-amendment/article/935/content-based

Lambiotte R, Delvenne J-C, Barahona M (2008) Laplacian dynamics and multiscale modular structure in networks. arXiv preprint arXiv:0812.1770

Legal Information Institute (2021a) Brandenburg Test. University Website. LII/Legal Information Institute. https://www.law.cornell.edu/ wex/brandenburg_test. Accessed 7 Jan 2021a

Legal Information Institute (2021b) Clarence BRANDENBURG, Appellant, v. State of OHIO. University Website. Cornell Law School/Legal Information Institute (LII). https://www.law.corne 11.edu/supremecourt/text/395/444. Accessed 7 Jan 2021b

Lewis M (2019) Don't F**k with cats: hunting an internet killerlNetflix official site. NETFLIX. 2019. https://www.netflix.com/title/81031 373

Massaro VA, Mullaney EG (2011) The war on teenage terrorists: Philly's 'flash mob riots' and the banality of post-9/11 securitization. City 15(5):591-604. https://doi.org/10.1080/13604813. 2011.630856

Mitchell DO, Boyod A (2012) Tactic: flash mob. Beautiful trouble a toolbox for revolution (blog). June 2012. https://beautifultrouble. org/tactic/flash-mob/

Mohilever YS (2012) Taking over the city: developing a cybernetic geographical imagination-flash mobs and Parkour. In: Dinulović R, Krklješ M, Graĉanin O (eds) Theatre space after 20th century, thematic proceedings of the 4 th international scientific conference in the cycle spectacle-city-identity. Department of Architecture and Urbanism, Faculty of Technical Sciences, Novi Sad, p 196

Molnár V (2014) Reframing public space through digital mobilization: flash mobs and contemporary urban youth culture. Space Cult 17(1):43-58. https://doi.org/10.1177/1206331212452368

Nicholson JA (2005) Flash! Mobs in the age of mobile connectivity. In: Mobility, new social intensities and the coordinates of digital networks, no. 6: 15 
Pratley N (2021) The Reddit flash mob won't be able to work the GameStop magic on silver. The Guardian. February 1, 2021. http://www.theguardian.com/business/nils-pratley-on-finance/ 2021/feb/01/reddits-flash-mob-wont-be-able-to-work-the-games top-magic-on-silver

"Raves/Raving" (2021) Encyclopedia. Encyclopedia of recreation and leisure in America. June 16, 2021. https://www.encyclopedia. $\mathrm{com} /$ humanities/encyclopedias-almanacs-transcripts-and-maps/ ravesraving

Rheingold H (2002) Smart mobs: the next social revolution. Basic Books

Says, Fisher L (2011) How Furman University got more than 50,000 views with a flashmob. Collegewebeditor.Com. May 16, 2011. https://collegewebeditor.com/blog/index.php/archives/2011/05/ 16/how-furman-university-got-more-than-50000-views-with-aflashmob/

Schols AMR, Willemsen RTA, Bonten TN, Rutten MH, Stassen PM, Kietselaer BLJH, Dinant G-J, Cals JWL (2019) A nationwide flash-mob study for suspected acute coronary syndrome. Ann Fam Med 17(4):296-303. https://doi.org/10.1370/afm.2401

Semler MW, Stover DG, Copland AP, Hong G, Johnson MJ, Kriss MS, Otepka H, Wang L, Christman BW, Rice TW (2013) Flash mob research a single-day, multicenter, resident-directed study of respiratory rate. Chest 143(6):1740-1744. https://doi.org/10. 1378/chest.12-1837

Shannon C (2020) Research guides: grey literature: overview. November 20, 2020. https://guides.lib.umich.edu/c.php?g=283076\&p= 1886023

Shapiro A (2017) The medium is the mob. Media Cult Soc 39(6):930 941. https://doi.org/10.1177/0163443717692740

Shawyer SE (2008) Radical street theatre and the Yippie legacy: a performance history of the youth international party, 1967-1968

Shresthova S (2013) Bollywood dance as political participation? On flash mobs, new media, and political potential. Converg Int J Res New Med Technol 19(3):311-317. https://doi.org/10.1177/13548 56513486532

Soep E (2012) The digital afterlife of youth-made media: implications for media literacy education. Comun Med Educ Res J 20(1):93-100

Staff, Examiner (2011) The evolution of flash mobs from pranks to crime and revolution. The San Francisco Examiner. August 28, 2011. https://www.sfexaminer.com/national-news/the-evolutionof-flash-mobs-from-pranks-to-crime-and-revolution/

Staff, Washington Post (2021) Woman dies after shooting in U.S. Capitol; D.C. National Guard Activated after mob breaches building. Washington Post, January 6, 2021. https://www.washingtonpost. com/dc-md-va/2021/01/06/dc-protests-trump-rally-live-updates/

Steinblatt H (2011) E-incitement: a framework for regulating the incitement of criminal flash mobs, 43

Sykes D, Magee J, Kramer J (2011) FlashMob: distributed adaptive self-assembly. In: Proceeding of the 6th international symposium on software engineering for adaptive and self-managing systems-SEAMS'11, 100. ACM Press, Honolulu. https://doi.org/ 10.1145/1988008.1988023

Tan E, Bakar BA (2015) Experiencing the flash mob: meanings and experiences in an unplanned event in Singapore, 9

Thomas V (2020) Exemplars-software engineering for self-adaptive systems. Self-Adaptive.Org (blog). October 8, 2020. https://www. hpi.uni-potsdam.de/giese/public/selfadapt/exemplars/

Tonkin E, Pfeiffer HD, Tourte G (2012) Twitter, information sharing and the London riots? Bull Am Soc Inf Sci Technol 38(2):49-57. https://doi.org/10.1002/bult.2012.1720380212

Trachtman P (2006) A brief history of Dada. Smithsonian Magazine. May 2006. https://www.smithsonianmag.com/arts-culture/dada$115169154 /$

Tsou YZ (2015) Digital natives in the name of a cause. From 'flash mob' to 'human flesh search. Meson Press, pp 179-195

Tucker E, Watkins T (2011) More flash mobs gather with criminal intent. NBC News. August 9, 2011. https://www.nbcnews.com/ id/wbna44077826

Turner RH, Killian LM (1957) Collective behavior, vol 3. PrenticeHall, Englewood Cliffs

University F (2011) Flash mob. Furman Mag 54(2):2

Vellar A (2012) The recording industry and grassroots marketing: from street teams to flash mobs. Particip J Audience Recept Stud 9(1):24

Venning W (2012) Funk up your Japanese with a flashmob!, 8

Wainwright LS (2019) Happeningldefinition, history, artists, and facts. In: Encyclopedia Britannica. July 10, 2019. https://www.brita nnica.com/art/Happening

Walker R (2011) Eight is not enough: a historical, cultural, and philosophical analysis of the flash mob, 186

Warner A (2005) A brief history of the anti-globalization movement. Univ Miami Int Comp Law Rev 12(2):237-268

Wasik B (2011) \#Riot: self-organized, hyper-networked revolts-coming to a city near youlforget anarchy. With social media, today's protests are networked, mobile, and everywhere. Blogsite. WIRED. December 16, 2011. https://www.wired.com/2011/12/ ff-riots/

Whiteker JS (2010) Flash mob dance: empowering survivors. Clin J Oncol Nurs 14(6):679-680. https://doi.org/10.1188/10.CJON. 679-680

Yiming G (2015) Flash mob-Urban-Urbanite, 23

Zeitz KM, Tan HM, Grief M, Couns PC, Zeitz CJ (2009) Crowd behavior at mass gatherings: a literature review. Prehosp Disaster Med 24(1):32-38

Zellner A, Sloan C, Koehler MJ (2011) The educational affordances of the flash mob: from mobs to smart mobs, 7

Publisher's Note Springer Nature remains neutral with regard to jurisdictional claims in published maps and institutional affiliations. 